\title{
Democracias representativas en crisis. Democracia participativa y mecanismos de participación ciudadana como opción
}

\section{Representative democracies in crisis. Participatory democracy and citizen participation as an option}

\author{
María Laura Eberhardt ${ }^{1}$ \\ Universidad de Buenos Aires (Argentina)
}

Recibido: 06-05-14

Aprobado: 14-10-14

\section{Resumen}

Los mecanismos de participación ciudadana han sido debatidos, incorporados y utilizados (aunque en cantidad, frecuencia y con resultados diferentes) en numerosas democracias. Especialmente en aquellas atravesadas por la crisis de representación desde fines de los '80, que siguió a la ruptura del Estado de Bienestar y al paso al denominado Estado de la Era Global. Estos institutos introducen canales semidirectos para la participación civil en el proceso de política pública, a fin de oxigenar las descreídas instituciones verticales de la democracia representativa electoral. Conocer el contexto histórico y teórico de su adopción permitirá comprender mejor el sentido y alcance de esas herramientas como respuestas ante tal escenario de desafección cívica.

Palabras-clave: Crisis de la representación, Mecanismos de participación ciudadana, Democracia Participativa, Ciudadanía.

\footnotetext{
${ }^{1}$ (laura rafaela@yahoo.com.ar). Doctora en Ciencia Política (UNSAM), Magister en Ciencia Política y Sociología (FLACSO), Licenciada en Ciencia Política (UBA), Posdoctorado de la Facultad de Derecho (UBA). Publicaciones recientes: Siga participando... dedicado a los ciudadanos de las democracias reales. Los mecanismos de participación y control societal en la Ciudad de Buenos Aires. Buenos Aires, Prometeo, 2013; Introducción a la sociología (con Villanueva, E. y Nejamkis, L). Florencio Varela, Editorial UNAJ, 2012; Sobre la huella de Constant: La crisis de representación y el retorno a la participación ciudadana, "Revista Leviathan. Cuadernos de Investigación Política", $\mathrm{n}^{\circ}$ 7, Universidade de São Paulo, Departamento de Ciencia Polîtica, Brasil, 2013 (disponible en http:// www.fflch.usp.br/dcp/leviathan/index.php/leviathan/article/view/190/pdf_13).
} 


\begin{abstract}
Citizen participation mechanisms have been discussed, built and used (although in quantity, frequency and with different results) in many democracies. Especially in those crossed by the crisis of representation since the late ' 80 s, following the breakdown of the welfare state and the transition to the State of the Global Era. These semidirect institutes introduce direct channels for citizen participation in the public policy process in order to oxygenate the discredited vertical indirect electoral institutions of representative democracy. Knowing their critical and theoretical context of adoption will allow us a better understanding of the meaning and scope of these tools as responses to such civic disaffection.
\end{abstract}

Key-words: Crisis of representation, Citizen participation mechanisms, Participatory Democracy, Citizenship.

\title{
1. Introducción
}

Los mecanismos de participación ciudadana, como la iniciativa popular, la consulta popular, la audiencia pública, el presupuesto participativo, los consejos consultivos, los jurados ciudadanos, el plan estratégico, la revocatoria de mandato, entre otros, han sido debatidos, incorporados y utilizados (aunque en cantidad, frecuencia y con resultados diferentes) en numerosas democracias occidentales. Especialmente en aquellas atravesadas por la llamada crisis de representación desde finales de los años ' 80 , que prosiguió a la ruptura del modelo de Estado de Bienestar y al paso al Estado de la era global ${ }^{2}$.

La incorporación de tales institutos semidirectos se enmarca, en la clasificación de Vincenzo Ferrari, dentro de la función del derecho referida a la legitimación del poder: "aquí poder se entiende como participación en la toma de decisiones. La función se funda en que todos los sujetos que disponen de capacidad de decisión o que deciden ampliarla, hacen uso normal del derecho para conseguir consenso sobre las decisiones que asumen o que desean asumir"3.

Y ello debido a que, frente a la pérdida de credibilidad tanto de los gobernantes elegidos a través del voto popular como respecto del funcionamiento de los órganos representativos tradicionales, fueron los propios mandatarios quienes decidieron adoptar otros canales institucionales que habilitasen una mayor participación ciudadana en la discusión, acuerdo e implementación de las políticas públicas. El fin que perseguían era el de corresponsabilizar a los ciudadanos en tales decisiones y aumentar su nivel de aceptación y legitimidad en la sociedad.

\footnotetext{
2 Juan Manuel Abal Medina, Manual de ciencia política, Buenos Aires: Eudeba, 2010, págs. 114-117.

${ }^{3}$ Felipe Fucito, Sociología del Derecho. El orden jurídico y sus condicionantes sociales, Buenos Aires: Editorial Universidad, 1990, pág. 286.
} 
La creación y aplicación de tales mecanismos en los regímenes representativos modernos se impulsó entonces con la intención de que funcionasen como canales alternativos $\mathrm{y} / \mathrm{o}$ complementarios de las tradicionales instituciones electorales y partidarias en situación crítica. Siendo mecanismos que hacían posible la presentación de las demandas ciudadanas en forma más directa en las instancias indirectas de toma de decisiones políticas.

Varios pensadores contemporáneos también recomendaron la creación y puesta en práctica de instrumentos participativos a los fines de acortar o revertir la creciente distancia, desconfianza y apatía que se fue produciendo en la relación entre representante y representado, principalmente una vez dejado atrás el llamado "municipio de bienestar" y arribado el nuevo municipio de tipo "relacional"4. Ello posibilitaría un mayor y más directo acceso de las opiniones y propuestas de la sociedad civil al proceso de política pública. De este modo, se esperaba poder adoptar decisiones que gozaran de un más alto nivel de consenso, legitimidad y corresponsabilidad social.

\section{Democracia, representación y participación a la luz de la teoría política moderna}

Conscientes de la centralidad adquirida por el modo representativo de organización de las repúblicas y de la amplia vigencia del mismo en el tercer milenio, como también de los déficits que en la actualidad enfrenta tal modelo, en este apartado realizaremos un breve acercamiento a los primeros esbozos a favor de una revalorización e la participación ciudadana emitidos por algunos de los más reconocidos teóricos modernos de la democracia y la representación.

Uno de los autores claves que ha analizado en forma crítica a la democracia representativa en comparación con la democracia directa es Jean Jacques Rousseau, para quién la libertad no era compatible con la representación. Por el contrario, entendía por libertad política la participación personal y activa de los ciudadanos en la decisión conjunta sobre los asuntos públicos comunes, la que sólo podía realizarse en un tipo de organización republicana al estilo de la democracia directa donde el Poder Legislativo soberano fuese ejercido por el pueblo en su totalidad, mientras que el Ejecutivo, encargado meramente de aplicar las leyes por aquél dictadas, sería simplemente un órgano representativo subordinado a las decisiones supremas de la Voluntad General.

${ }^{4}$ Quim Brugué, Joan Font y Ricard Gomá, "Participación y democracia. Asociaciones y poder local, en M. Funes y R. Adell, Movimientos sociales: cambios social y participación, Madrid: UNED, 2003, págs. 5-6. 
Según este autor, "en el instante en que un pueblo se da representantes, ya no es libre; ya no es" ${ }^{\prime \prime}$. La libertad era para él un valor absoluto e innegociable ${ }^{6}$. Los pueblos modernos eran a sus ojos esclavos que, habiendo abolido la esclavitud del trabajo, enajenaban su libertad en manos de sus representantes, para someterse a la esclavitud del ámbito privado.

Una postura en parte contestataria de la anterior y más claramente liberal es la de Benjamin Constant, crítico del concepto de libertad de Rousseau, al que consideraba extra-temporal al estar asociado a la irreproducible democracia directa de la antigua Atenas. Contrariamente, bajo las nuevas condiciones de los Estados modernos sería necesario para él asumir un significado diferente de libertad, en tanto "disfrute apacible de la independencia privada". En el marco de la modernidad los alcances de la libertad fueron redefinidos como las "garantías concedidas por las instituciones" a los disfrutes privados y el gobierno representativo devino, para Constant, en "el único que puede proporcionarnos hoy cierta libertad y tranquilidad"; el que, siendo "un descubrimiento de los modernos", "fue prácticamente desconocido entre las naciones libres de la Antigüedad".

Su postura era aquí opuesta a la de Rousseau, quien, a su criterio, confundía ambas libertades, causando infinitos males a pesar de sus nobles intenciones, a saber, la tiranía: "pedir a los pueblos de nuestros días que sacrifiquen, como los de antes, la totalidad de su libertad individual a la libertad política, es el medio más seguro para apartarles de la primera y, cuando eso se haya logrado, no se tardará en arrancarles la segunda".

No obstante, el concepto republicano de Constant no se limitó a la defensa del gobierno representativo, sino que postuló asimismo, como freno a la autoridad de dichos gobernantes y como resguardo de la libertad del ciudadano frente a éstos, un medio de vigilancia activa y constante: el derecho liberal de revocatoria de los poderes abusados ${ }^{10}$. Su solución apuntó a la combinación de ambos tipos de libertades bajo el gobierno representativo: la moderna, ligada al ámbito privado del individuo, y la antigua, unida a la participación en el poder político, aunque esta vez desde el voto, el control y la vigilancia ${ }^{11}$ : "Lejos pues, señores, de renunciar a ninguna de las dos clases de libertad de las que he hablado, es necesario (...) aprender a combinar una

\footnotetext{
${ }^{5}$ Jean Jacques Rousseau, "Del Contrato social", en Rousseau, J. J. Del Contrato social; Madrid: Alianza Editorial, 1998, pág. 122.

6 Ídem, pág. 32.

7 Benjamín Constant, "De la libertad de los antiguos comparada con la de los modernos", Conferencia pronunciada en el Ateneo de París, Febrero de 1819; Centro de Estudios Constitucionales - Universidad de Valladolid, 1989, pág. 4.

${ }^{8}$ Ídem, pág. 1.

9 Ídem, pág. 6.

${ }^{10}$ Ídem, pág. 7.

11 Ídem, pág. 8.
} 
con la otra"12; "la libertad individual, repito, es la verdadera libertad moderna. La libertad política es su garantía"13.

Otro de los autores que resaltó el valor de la participación ciudadana personal y activa respecto de los asuntos públicos en el marco de repúblicas representativas es Alexis de Tocqueville. También perteneciente a la tradición liberal, entendía a la democracia como un fenómeno social, el que podía ser acompañado o no por instituciones políticas acordes con la libertad. Este autor veía con temor el irrefrenable avance del principio democrático en tanto tendencia igualadora presente en la autopercepción de los individuos modernos, cuya peligrosidad radicaba en la posible derivación en una tiranía de la mayoría o en un despotismo de nuevo tipo basado en la concentración del poder y en la indiferencia de los ciudadanos respecto de las cuestiones generales.

Tal avance de la democratización social debía, a su parecer, encausarse por instituciones políticas que, sin contradecir las condiciones generales de igualdad, permitieran salvaguardar el espacio de ejercicio de la libertad. Dicha libertad era asumida como la participación activa en la cosa pública por parte del ciudadano, pero, en esta ocasión, a través de instituciones inmersas en el orden republicano representativo y de equilibrio/control de poderes, como ser: el sufragio universal, las asociaciones civiles, el gobierno municipal, a fin de contrarrestar la apatía y el aislamiento individualista moderno.

El autor daba así una nueva vuelta al esfuerzo de Constant por combinar el orden político representativo de los grandes Estados modernos (despreciado por Rousseau) con una libertad al estilo antiguo o rousseauniano de participación personal y activa en la administración de los asuntos comunes, pero, esta vez, en el ámbito acotado del gobierno local, donde la evidente cercanía entre gobernantes y gobernados fundía el interés particular del vecino con el interés general de la comunidad.

En síntesis, a pesar de que en la actualidad no resulta viable plantear con seriedad la posibilidad de retornar a alguna especie de organización política al estilo antiguo de las democracias directas, sino que, por el contrario, nos hallamos inmersos en un ineludible escenario de tipo representativo al que no podemos soslayar dadas las enormes dimensiones, complejidad y heterogeneidad de los Estados modernos, lo encontramos, sin embargo, experimentando hoy una fuerte crisis.

Es por ello que -aceptada cierta adecuación de la forma representativa de organización a las condiciones políticas modernas, asumida la impracticabilidad actual de la utopía rousseauniana de la Voluntad General y considerando las propuestas de un cierto equilibrio representativo-participativo constantiana y tocquevilliana - resulta preciso adentrarnos en el estado presente de nuestras democracias, a fin de revisar el grado de legitimidad que presentan sus sistemas

\footnotetext{
12 Ídem, pág. 8 .
}

13 Ídem, pág. 6. 
representativos de gobierno, al igual que sus perspectivas futuras de subsistencia.

La llamada "crisis de representación" por la que tales Estados atraviesan, tan evocada en nuestros tiempos, aparece, como veremos en el apartado siguiente, como un contundente cuestionamiento a los cimientos mismos de las democracias representativas vigentes en nombre de un sostenido reclamo por la apertura de nuevos espacios de participación ciudadana, al mejor estilo de los mecanismos semidirectos.

\section{La crisis de la representación}

La llamada "crisis de representación" es un concepto controvertido que caracteriza a una situación de extendida y profunda desconfianza y apatía de los ciudadanos respecto de sus gobernantes y del funcionamiento de las instituciones básicas de las democracias contemporáneas (partidos políticos, elecciones y poderes de gobierno), vigente desde los últimos 30 años.

Siguiendo la definición de Ferrater Mora, "crisis significa separación, abismo, algo singular y anormal que se produce en el curso de un ser, o mejor dicho, de un acontecer, pero de tal modo singular y anormal que implica el inevitable dilema de superar esa singularidad, esa anormalidad, o sucumbir" ${ }^{\prime \prime}$.

La crisis aquí referida indicaba, en términos de Manin, la metamorfosis de la democracia de partidos en la democracia de audiencia ${ }^{15} \mathrm{o}$, en los de Abal Medina, el paso del modelo de representación de masas (de 1910 a 1970) al modelo electoral (desde 1980) ${ }^{16}$.

A principios del siglo XX Michels ya vislumbraba una propensión que iría en aumento hacia fines del período: que la forma externa democrática que caracterizaba la vida de los partidos políticos bien podía enmascarar (para los observadores superficiales) la tendencia a la aristocracia, o mejor dicho, hacia la oligarquía, que era propia de toda organización de partido.

En tal sentido las organizaciones más fuertes resultaban ser las menos democráticas. Un empleado o mandatario se convertía en líder, con una autonomía y libertad de acción que no debía tener, y se acostumbraba a resolver por sí solo cuestiones importantes. En esa concentración de poder en las organizaciones partidarias y en sus líderes, en ese distanciamiento del representante respecto de sus representados, en esa concentración y manejo discrecional de los recursos de poder por las elites políticas, terminaría forjándose la crisis representativa.

Piedra Buena sumó a ello el concepto de desciudadanización, por el

\footnotetext{
14 Op. cit. en Mario Justo López, La crisis de los partidos políticos. Estructura y vigencia en la Argentina, Buenos Aires: Cooperadora de Derecho y Ciencias Sociales, 1963, pág. 72.

15 Bernard Manin, The Principles of Representative Government, Cambridge: Cambridge University Press, 1997, pág. 197.

16 Juan Manuel Abal Medina, Manual de ciencia política, op. cit., págs. 146-149.
} 
que entendía "un marcado desinterés por la cosa pública, donde la cultura política juega un rol clave" 17 . Hablaba de un nuevo hombre, el de la sociedad posindustrial, "descreído de la política a causa de la falta de respuestas válidas frente a los desafíos de la nueva realidad"18.

Como contracara de dicho fenómeno, el autor colocaba, "por un lado, una serie de formas de participación vinculadas con la solidaridad"; y, por otro, "una sucesión de prácticas políticas tales como cacerolazos, cortes de rutas, bloqueo de edificios, ocupación de empresas cerradas, etc". Estas últimas eran calificadas como "demandas sociales anárquicas, verdaderas formas de participación inusitadas y autoconvocantes, en búsqueda de otros canales alternativos eficaces, frente al desinterés puesto de manifiesto por los partidos políticos en el tratamiento y solución de problemáticas socioeconómicas acuciantes de la sociedad"19.

\section{Diagnosticando la crisis representativa}

La crisis representativa sacudió entonces los pilares de los regímenes indirectos siendo que los parlamentos y los congresos de las democracias modernas ya no se correspondían con la visión de un cuerpo que reproducía la deliberación ideal que la totalidad de la sociedad hubiera llevado a cabo por sí misma en caso de haber sido practicable ${ }^{20}$.

Simultáneamente, muchas de las deficiencias de los parlamentos reflejaban las deficiencias de los partidos, los que lejos estaban de cumplir con las funciones atribuidas como "vehículos necesarios para conducir la discusión pública sobre la base de principios, ideologías o modelos de la sociedad”, así como de resultar "útiles para contrarrestar el poder de las facciones que unen a los individuos sobre la base de sus crudos intereses" ${ }^{21}$.

Como señalaba Nino, los partidos hoy en día se constituían como "coaliciones amorfas con una decreciente definición ideológica"22. La adhesión a un partido político se debía más a una cuestión de tradición familiar, lealtad personal y competencia de tipo deportiva que a una cuestión de compromiso ideológico. Asimismo, la mayor parte de la actividad política que tenía lugar dentro de los partidos se refería más a la competencia interna que al análisis de los problemas nacionales.

${ }^{17}$ Carlos, A. Piedra Buena, "Crisis de partidos políticos en la Argentina: aproximación a un diagnóstico de su situación actual”, en G. Ancarola et al, Calidad institucional o decadencia republicana, Buenos Aires: Lajouane, 2007, pág. 196.

18 Ídem, pág. 197.

19 Ídem, pág. 197.

${ }^{20}$ Carlos Nino, La constitución de la Democracia Deliberativa, Barcelona: Gedisa, 1997, pág. 237.

21 Ídem, págs. 237-238.

22 Ídem, págs. 237-238. 
Se observaba que:

Dado que los parlamentos y los partidos políticos son los principales canales aparte de la participación popular directa- a través de los cuales funciona la democracia deliberativa, sus deficiencias constituyen una debilidad primaria que afecta a la totalidad del sistema. Estas deficiencias explican con amplitud los pobres resultados morales del proceso democrático, a pesar de su alegada calidad epistémica, cuando este se aproxima a la práctica informal de la discusión moral ${ }^{23}$.

En la actualidad, la modernización social y tecnológica redujo la centralidad de los partidos como agentes de representación política, viendo disputado su rol histórico como organizadores de la sociedad civil por grupos de interés, movimientos sociales y Organizaciones No Gubernamentales $(\mathrm{ONG})^{24}$.

Además, la profesionalización de los partidos y su inclinación hacia funciones prioritariamente electorales, los desvinculó de sus bases sociales concentrándolos en los círculos del poder, redundando en una menor participación y en una mayor volatilidad del voto: "los individuos buscan una relación de transparencia con la política (en general desde lugares 'no políticos'), mediante un vínculo de tipo empático que desprecia cualquier tipo de mediación. Pero sin mediación no hay representación posible"25.

Si la sociedad contemporánea impidió el juego político representativo, el sistema de partidos tuvo entonces que adaptarse y llevar a cabo una transformación radical: "poco a poco fueron abandonando sus antiguos compromisos, prácticas y funciones para tomar su lugar en el juego político contemporáneo, que es cada vez más autorreferencial"'26.

Tal cualidad autorreferencial consiste en su capacidad de establecerse y reproducirse a sí mismo como sistema diferenciado a través de la producción continua de consenso y legitimidad. Su antiguo rol como mecanismo agregador y representante de voluntades políticas, surgidas de la base social, caducó frente a las nuevas realidades.

Tal evolución del sistema partidario y del sistema político en general, era un resultado lógico frente a un individuo que se desentiende de lo político. $\mathrm{Y}$ es que para el ciudadano medio lo político resulta "algo distante y remoto, un mundo 'sucio' plagado de comportamientos egoístas, estratégicos e hipócritas en el que él no tiene ninguna capacidad de acción. Esto lo lleva a un mayor desentendimiento con la política, que es empujada a su vez, a asumir mayores niveles de autorreferenciación" ${ }^{27}$.

\footnotetext{
23 Ídem, pág. 241.

${ }^{24}$ Kenneth Roberts, "El sistema de partidos y la transformación de la representación política en la era neoliberal latinoamericana”, en M. Cavarozzi y J. M. Abal Medina (comps.), El asedio a la política. Los partidos latinoamericanos en la era neoliberal; Rosario: Homo Sapiens, 2002, pág. 57.

25 Juan Manuel Abal Medina, La muerte y la resurrección de la representación politica; Buenos Aires: Fondo de Cultura Económica, 2004, pág. 105.

26 Ídem, págs. 105-106.

27 Ídem, págs. 106-107.
} 
Efectivamente, los partidos políticos, otrora componentes insoslayables de las democracias representativas modernas en tanto representantes claves de las divisiones de la sociedad en términos de intereses sectoriales y de propuestas de conducción social, se han visto seriamente amenazados en dicha función por el surgimiento de nuevos temas y conflictos.

Estas inquietudes novedosas (de género, medio ambiente, modernidad, globalización), no encuentran expresión en los viejos partidos surgidos de otros clivajes previos, y los partidos más recientes sólo los llegan a representar de uno a la vez, sin extenderse sobre los restantes. A esto se suma el desafío de la opinión pública que, a través de la "ilusión de las encuestas y los medios de comunicación", suele ser presentada como un actor social relevante ${ }^{28}$.

Respecto de lo último, García Lema subrayaba la importancia que revisten en nuestros días las mediciones o encuestas de opinión: "Ellas son reveladoras de que en la acción gubernamental existe una permanente referencia a la opinión ciudadana, a la que se sondea de modo habitual para constatar su grado de conformidad o disconformidad con las políticas en ejecución"29.

Por lo demás, la crisis económica y las reformas de libre mercado de las últimas décadas socavaron la lógica organizacional de los partidos obreros y las estructuras de clivaje estratificado del sistema de partidos en que se constituyeron. La precariedad, fragmentación y flexibilización de los mercados, diversificó los intereses e identidades de los trabajadores, desincentivando las organizaciones colectivas (como los sindicatos), ya profundamente debilitadas por la represión ${ }^{30}$.

Muchos de los movimientos sociales (de género, comunitarios, de derechos humanos, ecologistas, aborígenes, étnicos) surgidos a partir de dicha declinación y cambios; varios de ellos de índole local, con intereses heterogéneos, estructuras fragmentadas y aspiraciones de autonomía; no pudieron ser articulados por los partidos en un proyecto político común. Además, varias ONG desplazaron a los partidos y al Estado en la provisión de recursos a los actores sociales.

Para Piedra Buena, "las consecuencias prácticas de esta apreciación se traducen en el discurso ciudadano, que sostiene que ante la falta de credibilidad en los partidos, en cuanto a articuladores de demandas, su rol debe ser asumido por organizaciones de la sociedad civil"31. No obstante, el autor creía que la sociedad civil no podía reemplazar a los partidos. Si así lo hiciesen, algunas de las ONG que accionaban en su seno de hecho perderían de vista la finalidad básica que les había dado origen, para transformarse en nuevos partidos políticos.

\footnotetext{
${ }^{28}$ Manuel Antonio Garretón, Cambios sociales, actores y acción colectiva, CEPAL, 2001, pág. 375.

29 Alberto Manuel García Lema, La reforma por dentro. La dificil construcción del consenso constitucional, Buenos Aires: Planeta, 1994, pág. 258.

${ }^{30}$ Kenneth Roberts, "El sistema de partidos y la transformación de la representación política”, op. cit., pág. 70

${ }^{31}$ Carlos, A. Piedra Buena, “Crisis de partidos políticos en la Argentina”, op. cit., pág. 198.
} 
Por el contrario:

El rol del tercer sector sobre la vida política -verdadero embrión de una sociedad civil que comienza a tomar conciencia de sí misma- no es otro que el crecimiento de lo que ha dado en llamarse el capital social; lo que de suyo implica relaciones horizontales de reciprocidad y cooperación, actitudes de compromiso y participación en los asuntos públicos y el desarrollo de la confianza y la tolerancia ${ }^{32}$.

A lo anterior, Roberts agregaba su visión de que en estos tiempos ya "no se hallan promesas políticas ni ideológicas de distribución de beneficios colectivos a través del Estado para movilizar la participación

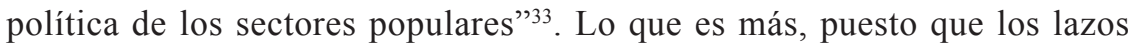
de los partidos con los actores sociales se volvieron cada vez más tenues, aquellos se relacionan con los electores más como individuos que eligen libremente que como miembros de la comunidad de fieles. Lo curioso es que los impulsores de tales políticas reestructuradoras fueron muchos de los partidos obreristas de antaño.

Por el contrario, la competencia partidaria de estos tiempos se caracteriza por tres tendencias. Primero, una des-institucionalización de la representación política, debido a que los votantes se han vuelto cada vez más independientes de las organizaciones.

Segundo, su desmasificación, consistente en el declive de las asociaciones secundarias de gran escala, de las estructuras organizacionales de base y de la propia militancia política, así como en la profesionalización de los partidos y las campañas electorales: "Aunque últimamente pueden pertenecer a organizaciones sociales o participar en el proceso político más individuos, éstos eligen vehículos más localizados o especializados de participación más que organizaciones de masas centralizadas que se hallan diseñadas generalmente para ejercer o influir sobre el poder del Estado" ${ }^{34}$.

Y, tercero, la verticalización de los lazos entre partido y sociedad, donde las antiguas formas horizontales de organización de intereses de clase y solidaridades dan lugar a redes verticales policlasistas que dependen de intercambios de favores materiales y políticos individualizados.

Estas tres tendencias dan cuenta de cierto retorno a un estilo de política oligárquica donde la competencia gira en torno de figuras notables que atraen a un conjunto diverso e indiferenciado de adherentes, pero sin utilizar la ideología o intereses de clase para la movilización política ${ }^{35}$.

\footnotetext{
${ }^{32}$ Carlos, A. Piedra Buena, "Crisis de partidos políticos en la Argentina”, op. cit., pág 199.

${ }^{33}$ Kenneth Roberts, "El sistema de partidos y la transformación de la representación política”, op. cit., pág. 71 .

34 Ídem, pág. 75.

35 Ídem, pág. 76.
} 
En la Argentina, paradójicamente, la consolidación democrática, alcanzada durante los años 90, trajo consigo el apartamiento de la gente respecto de la política y la privatización de la ciudadanía: "un distanciamiento entre sistema político y sociedad, desafección de la política y crisis del consenso fuerte y de expectativas respecto de un mundo mejor asociado a la política"36.

Las causas de la crisis rondaban la influencia de los sucesivos incumplimientos programáticos de los diferentes gobiernos; la creciente importancia que adquirió el fenómeno de la corrupción atribuido a toda la clase política; la situación social declinante de vastos sectores cuya principal responsabilidad recaía sobre los políticos; la profesionalización de la política, la cual aparecía como una mera gestión de negocios y de control; y la influencia de los medios de comunicación y de su concomitante desarrollo de una opinión pública más independiente e informada.

La drástica modificación de las relaciones de fuerzas entre política y economía, producida en los últimos 15 años en el marco del proceso de globalización, tuvo también gran influencia. Dicho proceso, redujo los márgenes de autonomía del Estado nacional al igual que la capacidad de la política de regular una economía desnacionalizada. Opuestamente, surgieron otros nuevos factores de poder: los grupos económicos, los organismos internacionales y los medios de comunicación, los que desplazaron a los sindicatos, a las fuerzas armadas, a las cámaras sectoriales y a la Iglesia. La capacidad decisoria del Estado se vio entonces acotada a la medida en que se realizaban los intereses de estos actores ${ }^{37}$.

La sensación resultante fue la de una democracia débil, "pero no en términos de una debilidad del régimen para reproducirse, sino de la política para reorientar la economía de acuerdo a fines sociales o encarar la realización del bien común"38. Las elecciones y los lazos de representación eran solamente una parte (y no la más importante) del proceso de estructuración de las relaciones de poder. Además, también aumentaban la necesidad y la dificultad de dominar la creciente complejidad social que muchas veces se escapaba de las posibilidades de la política tecnocrática.

Por último, se sumaba la mencionada transición a un nuevo modelo de representación que acompañaba el paso de un Estado de Bienestar a otro postsocial o neoliberal dominado por partidos catch all; bajo la creciente influencia de mecanismos de representación permanente como los sondeos de opinión; y tras el surgimiento y aplicación de nuevas instituciones como las audiencias públicas, el control del financiamiento partidario, la accountability en la gestión pública, entre otras.

\footnotetext{
${ }^{36}$ Daniel García Delgado, "Crisis de representación, nueva ciudadanía y fragmentación en la democracia argentina”, en S. Gaveglio y E. Manero (comps), Desarrollos de la teoría política contemporánea, Rosario: Homo Sapiens, 1998, pág. 120.

37 Daniel García Delgado, "Crisis de representación, nueva ciudadanía y fragmentación en la democracia argentina”, op. cit., pág. 125.

${ }^{38}$ Idem, pág. 125.
} 


\section{La crisis de representación en América Latina y en la Argentina}

Este fenómeno de crisis del lazo representativo se manifestó en gran cantidad de países del mundo a fines de los '80, tras la caída del modelo de Estado de Bienestar Keynesiano, frente a administraciones que ya no podían dar igual cantidad y calidad de respuestas a las necesidades de la población.

El paso del patrón de representación de masas (1910-1970) a otro de tipo electoral (1980-), provino de "la reducción del papel del Estado en la regulación de la vida cotidiana de los ciudadanos asociada con el predominio de la ideología neoliberal" 39 . A ello se sumó la creciente diferenciación social y el impacto de los medios masivos de comunicación.

La sociedad posindustrial emergió más desestructurada, heterogénea, fracturada, individualizada, cambiante, compleja, con nuevas identidades colectivas flexibles más voluntarias que orgánicas y tras la decadencia de los grandes grupos colectivos típicos de la anterior sociedad industrial.

Dominada por la "videopolítica" ${ }^{40}$, colmada por un creciente electorado independiente o flotante con menos determinaciones estructurales para el sufragio, acechada por la mayor relevancia de las coyunturas específicas y la personalización de las campañas, esta nueva sociedad hizo estallar por los aires la ilusión moderna de la representación política del mundo y provocó el debilitamiento de la creencia ilustrada en la capacidad articuladora de la política ${ }^{41}$.

Hacia el sur del planisferio:

Las sociedades latinoamericanas viven hoy una revolución desde la demanda. Informadas e impacientes, descreen de toda receta ideológica preconcebida y desconfían de sus gobernantes, legisladores, jueces, sindicalistas y empresarios -aunque tampoco reconozcan liderazgos de recambio-. Son sociedades informadas e impacientes, movilizadas en defensa de sus derechos, curtidas de decepciones y fracasos, aunque siempre dispuestas a apoyar a quienes ofrezcan ejemplos claros de compromiso, integridad y fortaleza de carácter ${ }^{42}$.

En efecto, "en América Latina, ciudadanos indignados luego de los procesos de transición demostraron su disconformidad provocando las caídas

39 Juan Manuel Abal Medina, Manual de ciencia política, op. cit., pág. 149.

${ }^{40} \mathrm{La}$ "videopolítica" es un término acuñado por Sartori para dar cuenta de un nuevo modo que adopta la representación contemporánea, signada por la creciente influencia de los medios masivos de comunicación: "Éstos reemplazan el lugar tradicional de la política (la calle, la plaza, el público) llevándola a las casas de los ciudadanos, aquella esfera de lo individual e íntimo. Si para hacer política los ciudadanos debían salir a la calle, concurrir a un local partidario o participar de una movilización, hoy parece bastarles con encender el televisor, llamar a los programas de radio o participar de encuestas de internet”, en Juan Manuel Abal Medina, Manual de ciencia politica, op. cit., pág. 150.

41 Ídem, pág. 150.

42 Enrique Zuleta Puceiro, "Las izquierdas en su laberinto", La izquierda en su laberinto (2006), págs. 1-2. [https://umshare.miami.edu/web/wda/hemisphericpolicy/ LaIZQUIERDAeNsU1ABERINTO1Mayo2006.pdf], [consulta: 10 enero 2013]. 
de presidentes, por ejemplo en Brasil (1992), en Venezuela (1993), en Ecuador (1997) y hasta en la propia Argentina (2001)"43. En este último país, durante los últimos años ocurría que:

Los nuevos indignados abominan de la política pero están dispuestos a soportarla todo lo que haga falta. Está en tela de juicio el sistema tradicional de representación y, por un buen tiempo, las soluciones tardarán en articularse. Desde este punto de vista, la contabilidad tradicional de la política tiene poco para aportar. No hay punto de comparación entre este nuevo género de movilización, cognitiva y afectiva y las manifestaciones populares propias de la política tradicional. Ningún líder, partido ni plataforma puede alcanzar la importancia de las nuevas convocatorias ${ }^{44}$.

Sin embargo, a la hora de idear respuestas emergerían las contradicciones:

Una gran paradoja es que la gente confía menos en los órganos encargados de gobernar que en otras instituciones que no tienen tal responsabilidad. Así, se retroalimentan ciertos procesos y determinadas conductas. Si los argentinos tuvimos como gran cuenta pendiente de nuestra cultura cívica el poco apego al cumplimiento de las leyes, ¿cómo cambiará tal comportamiento si el encargado de producirlas -el Congreso- goza de tan poca confianza? Si el Estado de Derecho debe ser regenerado a través de una mejora de la calidad de la Justicia, ¿cómo hacerlo frente a la desconfianza que impera frente a los jueces? ${ }^{45}$.

En la Argentina actual, luego de varios años de acontecida la explosión política y social de 2001, sucede que "los instrumentos de la democracia tradicional dejan paso a la intervención de una ciudadanía atenta y cada vez más impaciente"46. En adelante, "el conflicto de las interpretaciones no bastará para minimizar la importancia objetiva de los cambios cada vez más profundos que se vienen produciendo en las formas de manifestación política de la ciudadanía" 47 .

Sin ir más lejos, en 2012 y 2013 se elevaron protestas contra medidas o actitudes del gobierno nacional, reaparecieron las cacerolas y hubo salidas pacíficas a las calles, no sin previa convocatoria (a veces político partidaria, otras no) a través de las redes sociales.

${ }^{43}$ Salvador Martí i Puig, "Dos fechas de protestas ciudadanas. 15-M y 12-M: balance y retos", El Periódico, (15 de mayo de 2012), págs. 10-11 [http://archivo.elperiodico.com/ed/20120515/pag_010. html], [consulta: 24 marzo 2013].

44 Enrique Zuleta Puceiro, "Democracia de proximidad”, El Estadista, (30 de noviembre de 2012), pág. 1. [http://elestadista.com.ar/?p=2955], [consulta: 12 febrero 2013].

45 Mario D. Serrafero, "Calidad institucional: cuestiones y desafíos", en G. Ancarola et al Calidad institucional o decadencia republicana, Buenos Aires: Lajouane, 2007, pág. 25.

${ }^{46}$ Enrique Zuleta Puceiro, "Democracia de proximidad”, op. cit., pág. 1.

47 Ídem, pág. 1. 


\begin{abstract}
Para quienes tratan de ver la realidad profunda y a largo plazo de la política argentina, un análisis desapasionado del nuevo clima de movilizaciones enciende luces de alerta imposibles de ignorar. Un primer dato, avizorado ya en 2001 es que, al igual que la mayor parte de las sociedades actuales, la Argentina ha incorporado a sus prácticas políticas la perspectiva de lo que muchos denominan, en todo el mundo, una "democracia de proximidad" ${ }^{48}$.
\end{abstract}

Para Zuleta Puceiro, los instrumentos de la democracia tradicional (partidos, urnas, campañas, militancias y $\mathrm{PASO}^{49}$ ) dejaron lugar a la intervención, la vigilancia y el control de una ciudadanía informada, atenta y cada vez más impaciente. Este "nuevo actor (la ciudadanía impaciente e indignada) ocupa ya no sólo las plazas mayores de todas las ciudades del mundo: monopoliza también todos los segundos del encendido radial y televisivo de todas las señales públicas y privadas del espectro audiovisual" ${ }^{50}$.

Sin embargo, a diferencia del "que se vayan todos" ${ }^{51}$ de 2001, esta nueva ciudadanía "no sólo se opone: también propone, discompone y descompone" 52 . Ahora postula que sigan todos, que se hagan cargo de sus responsabilidades $\mathrm{y}$, sobre todo, que no pretendan representar ni expresar a nadie ${ }^{53}$.

\title{
6. La crisis de representación en España y en el mundo
}

Tras lo anterior, cabe recordar que la Argentina es sólo un capítulo más dentro de un vasto proceso extendido a lo largo y ancho de la geografía de las democracias contemporáneas: "Algunos porcentajes hablan a las claras de la nueva dimensión a la que ha entrado de lleno la política argentina, siguiendo tendencias comunes a casi todas las sociedades del mundo"54.

Efectivamente, en la España de 2011 explotaron los indignados: "el ánimo de la protesta del 15-M estaba conectado con lo que ocurría a nivel internacional. Anteriormente, ciudadanos de Islandia, Irlanda, Grecia y Portugal ya habían salido a las calles para protestar contra sus autoridades, y pocos meses antes también había estallado la primavera árabe" ${ }^{55}$.

\footnotetext{
48 Ídem, pág. 1.

49 Primarias Abiertas Simultáneas Obligatorias para la selección de candidatos electorales por los partidos.

${ }^{50}$ Enrique Zuleta Puceiro, "Democracia de proximidad”, op. cit., pág. 1.

${ }^{51}$ Esta fue la consigna principal que coreaba la ciudadanía autoconvocada en la Plaza de Mayo de la Ciudad de Buenos Aires los días 19 y 20 de diciembre de 2001, y que terminaron con la renuncia anticipada del Presidente Fernando De la Rúa.

52 Ídem, pág. 1.

53 Ídem, pág. 1.

54 Ídem, pág. 1.

55 Salvador Martí i Puig, "Dos fechas de protestas ciudadanas. 15-M y 12-M: balance y retos", op. cit., págs. 10-11.
} 
Para Serrafero, el movimiento de indignados en Europa mostraba una masa de jóvenes desilusionados con las promesas incumplidas del pasado, con un presente estático y un futuro sin horizontes. "Un mundo de indignados se ha alzado en el último período histórico. No reconoce territorios, culturas, ni fronteras ideológicas" $" 56$.

De este modo, la indignación de las multitudes en la calles cobró sus víctimas políticas, fuesen estos gobiernos democráticos o autoritarios ${ }^{57}$. Como observaba Serrafero los regímenes parlamentarios europeos podían reprimir las manifestaciones y actuar con sus fuerzas de seguridad sin por ello dejar de ser Estados democráticos. Pero los ciudadanos, a su manera, estaban reclamando una suerte de transición hacia otro tipo de democracia ${ }^{58}$.

En España, el 15-M constituyó un novedoso e inesperado movimiento de ciudadanos que realizaban protestas pacificas y que el 15 de mayo de 2011 se expresaron reclamando una democracia participativa, una "democracia real" y exclamando no ser mercancías de políticos y banqueros ${ }^{59}$.

Lo más llamativo de ese movimiento "fue su permanencia a lo largo del tiempo y su capacidad de resistir ocupando espacios públicos"60. Fue sobre todo una confederación de movilizaciones locales coordinadas en red, que no se agotaron con el desalojo de la Puerta del Sol o de la plaza de Catalunya"61. Por el contrario, tuvieron su eco en el 12-M de 2012 y 2013. En su segundo aniversario, los indignados reclamaron la dimisión al gobierno de Rajoy ${ }^{62}$.

De hecho, "el 15-M supuso una repolitización de un sector de la sociedad al mostrar una nueva cultura política ciudadana más crítica y exigente. También fue un evento de socialización política para una generación de jóvenes que salieron a la calle en contra de la estigmatización de ninistas que se les había asignado" 63 .

De igual modo, "constató la importancia de operar en red y horizontalmente a través de las redes sociales"64. Para Martí i Puig, "el 15-M fue un movimiento robusto precisamente porque no tuvo líderes ni conexiones partidarias, y porque impulsó demandas desde fuera de los canales institucionales" ${ }^{65}$.

\footnotetext{
${ }^{56}$ Mario D. Serrafero, "Un mundo indignado", El Estadista, (20 de septiembre de 2011), pág. 1. [http://elestadista.com.ar/?p=1349], [consulta: 20 abril 2013].

57 Ídem, pág. 1.

58 Ídem, pág. 1.

59 Ídem, pág. 1.

${ }^{60}$ Salvador Martí i Puig, "Dos fechas de protestas ciudadanas. 15-M y 12-M: balance y retos", op. cit., págs. 10-11.

${ }^{61}$ Ídem, págs. 10-11.

${ }^{62} \mathrm{NN}$ “Indignados exigen renuncia de Rajoy”, $D W$, (12 de Mayo de 2013), pág. 1. [http://www. dw.de/indignados-exigen-renuncia-de-rajoy/a-16808132], [consulta: 1 abril 2013].

${ }^{63}$ Salvador Martí i Puig, "Dos fechas de protestas ciudadanas. 15-M y 12-M: balance y retos", op. cit., págs. 10-11.

64 Ídem, págs. 10-11.

65 Ídem, págs. 10-11.
} 
Lejos de anclarse exclusivamente en España "el movimiento tuvo adhesiones y prolongaciones en distintas ciudades europeas: Londres, Lisboa, París, Roma, etc". El telón de fondo era la propia Europa ${ }^{66}$ :

La crisis griega, que no parece tener fondo, una España donde el desempleo es una sombra que no deja de pisar los talones de la gente y los ajustes que se reclaman en toda Europa son el marco cotidiano de una "ciudadanía de cornisa". Regímenes democráticos con ciudadanos indignados que toman las calles y reclaman cambios inmediatos son la moneda corriente que va en paralelo con la crisis económica y política de la eurozona. Recorte de gastos sociales, ajustes que no tienen fin y desmantelamientos de los recuerdos del Estado del Bienestar nos son medidas que aporten tranquilidad a la preocupación colectiva ${ }^{67}$.

\section{Finalmente:}

Las poblaciones del mundo árabe en rebelión volcadas en las calles han concluido con algunos regímenes autoritarios -y seguirán otros- y reclaman una transición hacia regímenes de tipo democrático. Tras la caída del presidente de Túnez, le siguió Egipto, las rebeliones en Libia (donde la Otan jugó un papel estelar) y las actuales protestas callejeras en Siria, salvajemente reprimidas por el régimen de la familia Al-Assad, todavía imperante ${ }^{68}$.

\section{Proponiendo salidas}

No obstante, a pesar de lo anterior, aún conserva cierta pertinencia la afirmación de que "no hay otro canal de representación más adecuado que los partidos cuando se trata de eventos políticos en que los ciudadanos tienen que elegir o tomar decisiones, como son las elecciones o el referéndum en diversos niveles, o cuando se trata de discusiones y decisiones legislativas" ${ }^{\prime 69}$.

En la misma línea, Serrafero sostiene que "nuestra democracia representativa descansa sobre los partidos políticos que son los que proveen las personas -supuestamente 'expertos'- que encararán la tarea de gobernar en el marco de un régimen competitivo, donde las distintas agrupaciones formulan sus ofertas de políticas públicas" $"$.

La circunstancia de que en la actualidad gocen de una "prácticamente inexistente confianza" en la población implica un hecho grave. Los partidos políticos han sido ubicados "en el centro de la escena", por ello, "sin un

\footnotetext{
${ }^{66}$ Mario D. Serrafero, "Un mundo indignado”, op. cit., pág. 1.

${ }^{67}$ Ibídem.

${ }^{68}$ Ibídem.

${ }^{69}$ Manuel Antonio Garretón, Cambios sociales, actores y acción colectiva, op. cit., pág. 375

${ }^{70}$ Mario D. Serrafero, “Calidad institucional: cuestiones y desafíos”, op. cit., pág. 26.
} 
cambio en los partidos, difícilmente se operará un salto cualitativo en nuestras instituciones"71.

Así, atender a la crisis del viejo modelo representativo no impide reconocer "la naturaleza centralmente 'electoral' de los regímenes democráticos modernos" " La democracia continúa siendo fundamentalmente vertical en su organización de gobierno, donde las instituciones electorales y representativas, a pesar de su crisis, permanecen como elementos indispensables del funcionamiento político de los Estados contemporáneos.

Entonces, "si la representación resulta cada vez menos creíble, desprovista de su substrato social y político, y no logra generar una legitimidad sólida a las democracias, es imprescindible encontrar herramientas institucionales que la fortalezcan": "esta será la clave de la reconstrucción de la legitimidad de la representación" "73.

Numerosos y diversos fueron los diagnósticos y las propuestas de salida de la crisis representativa, ideados desde sus mismos comienzos:

Samuel Huntington, Michel Crozier y Joji Watanuki manifestaron un claro apoyo al pluralismo o a una visión elitista de la democracia. Creen que la crisis es causada por una sobrecarga de demandas populares sobre un sistema que no las puede satisfacer y recomiendan el uso de mecanismos que limiten la expresión de esas demandas. En contraste con esta propuesta, C. B. Macpherson, quién argumenta a favor de una concepción populista de la democracia, piensa que la crisis de las democracias pluralistas actuales es producto de las desigualdades causadas por la falta de participación. La propuesta de Macpherson consiste en incrementar la forma en la que los ciudadanos intervienen en política ${ }^{74}$.

Asimismo, se ha señalado como conveniente emprender "un doble proceso de fortalecimiento de la representación política". Por un lado, "adecuando las viejas instituciones de la democracia representativa de masas al contexto actual, lo que significa concretamente ciudadanizar y personalizar aspectos y ámbitos importantes de los ordenamientos políticos" $" 75$.

Y, por el otro, el fomento de la participación ciudadana activa. Junto con la adecuación o mejora de los canales representativos tradicionales, la reconstrucción de la legitimidad política también implica una transformación más audaz e importante que consiste en volver a mirar las instituciones clásicas de la democracia entendida como autogobierno ${ }^{76}$.

Estas herramientas, "de la democracia participativa", han existido en el constitucionalismo occidental desde hace al menos medio siglo, y vienen hoy

\footnotetext{
71 Ídem, pág. 26.

72 Juan Manuel Abal Medina, La muerte y la resurrección, op. cit. pág. 108.

73 Ídem, pág. 114.

${ }^{74}$ Carlos Nino, La constitución de la Democracia Deliberativa, op. cit., pág. 214.

75 Juan Manuel Abal Medina, La muerte y la resurrección, op. cit. pág. 114.

76 Ídem, págs. 119-121.
} 
a reforzar la representación política en situación crítica, muy lejos de pretender eliminarla, reemplazarla o soslayarla.

Entendidos como herramientas para lograr una participación más activa de los ciudadanos en la cosa pública, "estos mecanismos (referéndum, plebiscitos, iniciativas legislativas, etc.) han estado siempre en tensión con los instrumentos representativos, los partidos políticos especialmente" 77 . Así como también con los gobernantes, a cargo de implementar un instrumento cuyo accionar llega a rozar su ámbito de poder, sus funciones y sus intereses en el cargo.

Sin embargo, resulta cada vez más aceptada la apreciación de que:

Frente a la debilitada representación postsocial, la construcción de un andamiaje institucional participativo puede no ser solamente el anhelo de quienes seguimos creyendo que el ideal del autogobierno vale la pena, sino la necesidad de todos aquellos que sienten que las actuales democracias desprovistas de la legitimidad popular pueden ir vaciándose progresivamente de contenido ${ }^{78}$.

Los institutos semidirectos cobran en este contexto gran interés y relevancia. En efecto, muchas constituciones y legislaciones nacionales y locales de América Latina y Europa han venido emprendiendo desde los años ' 90 reformas políticas que incluyen la creación de mecanismos de participación ciudadana, destinados a complementar las cuestionadas instituciones representativas con otras vías alternativas de intervención directa de la ciudadanía en la toma de decisiones públicas.

La también llamada democracia directa gana en adelante un lugar cada vez mayor en la ingeniería institucional, en la práctica democrática y en los estudios especializados de estos países durante los últimos años. La tendencia a expandir los mecanismos de democracia directa fue "en busca de mayores niveles de participación ciudadana para corregir la crisis de representación y hacer frente a los problemas de gobernabilidad"79. Así, el proceso de democratización política se acompañó “por la proliferación de mecanismos de participación, tanto formales como informales, de Democracia Directa" $"$.

A su vez, cabe destacar que:

(...) entre los distintos mecanismos de participación, es importante fomentar aquellos que por su lógica "deliberativa" no reproduzcan simplemente el funcionamiento de los procedimientos electorales, sino que abran espacios horizontales para la identificación de los problemas, la discusión de políticas y la

77 Ídem, pág. 121.

78 Ídem, pág. 122.

79 Daniel Zovatto, "Las instituciones de la democracia directa a nivel nacional en América Latina. Balance comparado: 1978-2007”, op. cit., pág. 262.

${ }^{80}$ Gabriela Ippólito, "Bajo la sombra de Atenas. Avances y Retrocesos de la Democracia Directa en América Latina”, Conferencia Internacional Democracia Directa en América Latina, Research Centre on Direct Democracy - UNSAM - IDEA, 14-15 de marzo de 2007, Buenos Aires, pp. 1-10, disponible en http://www.dd-la.ch/download/Ippolito.pdf, pág. 2. 
construcción de consensos. La implementación y extensión de estos ámbitos, de los que existen experiencias interesantes a nivel local, permitirían volver a interesar a los ciudadanos en el proceso de la toma de decisiones públicas, recuperando en algún sentido el ideal de la ekklesía o asamblea clásica ${ }^{81}$.

Efectivamente, en este escenario crítico los mecanismos de participación ciudadana fueron incorporados como otras formas institucionales para la expresión de la población, de modo que pudieran convertirse en instancias alternativas, pero fundamentalmente también en complementarias, de las vías de representación electorales y partidarias. El reforzamiento y ampliación de la democracia, era el objetivo prioritariamente buscado.

\section{Recapitulando}

En medio del referido clima general de descontento popular respecto del desempeño de las instituciones de gobierno, los parlamentos se percibían como "lugares donde reina la politiquería y la verbosidad, con lobbistas operando detrás de la escena y con un funcionamiento permanentemente ineficiente y lento" 82 .

Por su parte, los partidos políticos simbolizaban "grupos corporativos que defienden sus propios intereses" ${ }^{" 83}$. Numerosos países se sumergían de este modo en una profunda crisis de representación política, evidente desde fines de los años '80.

Específicamente en Latinoamérica, los partidos políticos enfrentaban una situación paradojal según la cual, si bien por un lado asistían a un proceso de consolidación democrática, por el otro enfrentaban una grave crisis de las modalidades de articulación y de representación de los intereses ciudadanos ${ }^{84}$. Un "síndrome de consolidación democrática con creciente inestabilidad (e ilegitimidad) de la política" ${ }^{85}$. Su impacto sobre los mecanismos de formación y expresión de las demandas sociales alejaría a los ciudadanos de la actividad partidaria y debilitaría el sustento de la legitimidad del sistema.

En tal contexto, los mecanismos de participación ciudadana fueron concebidos por juristas, teóricos y políticos, como herramientas semidirectas útiles para ser incorporadas en las democracias representativas, llamadas por

\footnotetext{
${ }^{81}$ Juan Manuel Abal Medina, La muerte y la resurrección, op. cit. pág. 122.

${ }^{82}$ Carlos Nino, La constitución de la Democracia Deliberativa, op. cit., pág. 237.

83 Ídem, pág. 238.

${ }^{84}$ Marcelo Cavarozzi y Esperanza Casullo "Los partidos políticos en América Latina hoy: ¿Consolidación o crisis?”, en M. Cavarozzi y J. M. Abal Medina (comps.) El asedio a la política. Los partidos latinoamericanos en la era neoliberal; Rosario: Homo Sapiens, 2002, pág. 9.

85 Ídem, pág. 15.
} 
esto "impuras" 86 , para permitir a los ciudadanos participar en la elaboración y adopción de decisiones públicas a partir de la combinación de elementos propios de la democracia directa e indirecta.

Dicho carácter "impuro" calificaría a la forma que podrían asumir ciertas democracias representativas contemporáneas en razón de agregar a su marco institucional indirecto diferentes mecanismos novedosos que habilitasen una participación ciudadana más directa: "Las instituciones de democracia semidirecta, que se han divulgado notablemente en las últimas décadas, responden a requerimientos de mayor participación ciudadana en la conducción de los negocios públicos, que no encuentran satisfacción plena en el mero ejercicio del sufragio" $"$.

El objeto de estos mecanismos semidirectos era el de colaborar con el difícil desafío de acotar la peligrosamente creciente brecha abierta entre representantes y representados, "permitiendo acercar la toma de decisiones a los ciudadanos" $"$.

$\mathrm{Su}$ condición semidirecta consistía en que, por un lado, "estas herramientas involucran de manera directa a la sociedad civil en los asuntos del Estado, abriendo un camino de participación para el conjunto de la ciudadanía"89. Así, "su implementación ofrece no sólo la posibilidad de que los individuos se involucren de manera directa en asuntos de interés general, sino que además acerca a los representantes con sus representados, reduciendo la distancia que los separa"90.

Pero, por otro lado, subsistían dentro de, y su funcionamiento se encontraba atravesado por, las instituciones y formas representativas de la democracia indirecta, cuyos pilares eran los partidos políticos y los gobernantes electos. Instituciones que, si bien se encontraban en crisis de credibilidad, seguían siendo centrales en los vastos y complejos Estados democráticos contemporáneos.

Respecto del rol de estos mecanismos semidirectos dentro de las democracias contemporáneas se enfrentarían pronto dos percepciones. Una según la cual existía una contraposición peligrosa entre la democracia representativa y la directa, con el subsiguiente riesgo de un posible uso demagógico de estas instituciones. Y la otra, para la cual tal supuesta contradicción era cosa del pasado, ya que, como la experiencia comparada lo demostraría, las instituciones de democracia directa, más que una alternativa per se, debían ser vistas como un complemento de la democracia representativa ${ }^{91}$.

\footnotetext{
${ }^{86}$ Mario Justo López, Manual de derecho político, Buenos Aires: Depalma, págs. 468-469.

87 Alberto Manuel García Lema, La reforma por dentro. La dificil construcción del consenso constitucional, op. cit., pág. 257.

88 Julieta Taboada, "Democracia Semidirecta en América Latina", Observatorio Electoral Latinoamericano, (2005), pág. 3; [http://www.observatorioelectoral.org/informes/documentos/ data/2006-04-05-juli-taboada.pdf], [consulta: 1 abril 2013].

89 Ídem, pág. 4.

90 Ídem, pág. 4.

91 Daniel Zovatto, "Las instituciones de la democracia directa a nivel nacional en América Latina.
} 
García Lema, en línea con Bobbio, concordaría con la segunda postura, según la cual "democracia representativa y democracia directa no son dos modelos o regímenes alternativos, sino que se trata de situaciones que pueden integrarse recíprocamente" 92 .

Una tercera postura podría reconocer en cambio la convivencia de ambas instituciones en los regímenes representativos "impuros", cuya vinculación, como alternativas o complementarias, dependería de la coyuntura, la voluntad política y el comportamiento ciudadano, pudiendo oscilar en sus grados de representación y participación según cómo se modificaran sus entornos.

En términos empíricos, no fueron pocos los ensayos de estas experiencias semidirectas en el mundo occidental, ni breve la trayectoria que recorrieron hasta el momento. Por ejemplo, "debido en parte a la influencia de los populistas a fines de las décadas de 1880 y 1890 , varios estados y ciudades de Estados Unidos adoptaron procedimientos de iniciativa popular, referéndum y revocatoria de mandatos"93.

El auge en la incorporación de estos mecanismos se consolidó con su extensión y arribo a otras numerosas naciones y localidades del mundo. De hecho, "las constituciones de muchos países occidentales, como las de Suiza, Francia, Italia, España, Canadá, Australia, Uruguay, Brasil y Chile, establecen diferentes posibilidades de participación popular directa"94.

En la Argentina, los cambios institucionales procuraron "rediseñar el proceso democrático y modificar la relación entre los ciudadanos y sus representantes" $"$. No obstante, la cantidad y frecuencia de ocasiones en que los diferentes mecanismos participativos fueron utilizados hasta el momento en el nivel nacional han sido sumamente escasas. Lo mismo puede decirse a nivel local de su capital, la Ciudad de Buenos Aires.

Lo anterior fue demostrado en el hecho de que, habiendo transcurrido varios años desde la incorporación de algunos instrumentos de democracia semidirecta en la Constitución Nacional (en 1994), y luego también reglamentados, "la incidencia de estos nuevos institutos en el escenario público ha sido casi nula"96. A nivel nacional, se implementaron "sólo unas pocas experiencias de iniciativas populares, de las cuales una sola concluyó con la sanción de la respectiva ley. En cambio, no se ha puesto en marcha ninguna consulta"97.

Balance comparado: 1978-2007”, en A. Lissidini, Y. Welp y D. Zovatto, Democracia Directa en Latinoamérica, Buenos Aires: Prometeo, 2008, pág. 255.

92 Alberto Manuel García Lema, La reforma por dentro. La difícil construcción del consenso constitucional, op. cit., pág. 257-258.

${ }_{93}$ Carlos Nino, La constitución de la Democracia Deliberativa, op. cit., págs. 205-206.

94 Ídem, pág. 206.

95 Ídem, pág. 206.

${ }^{96}$ Daniel A. Sabsay, "La participación ciudadana en la toma de decisiones en el Derecho Público Argentino"; Conferencia Internacional Democracia Directa en América Latina; Organizada por Research Centre on Direct Democracy - UNSAM - IDEA; Buenos Aires; (14 y 15 de marzo de 2007), págs. 5-6; [http://www.dd-la.ch/download/Sabsay_Daniel.pdf], [consulta: 17 abril 2013].

97 Ídem, pág. 5-6. 
En efecto, los mecanismos participativos pueden ser aptos en su concepción para el cumplimiento de sus fines más elevados, pero su desempeño está sujeto a los límites reales que se presentan al momento de ser implementados. Ciertamente, "las intenciones políticas de quienes promueven la aprobación de los mecanismos nada nos dice respecto a los usos y efectos de los mismos"98.

Por un lado el empleo de estos institutos semidirectos podría "contribuir a transformar la democracia (...) democratizando la agenda política y promoviendo la participación ciudadana" utilizar estas herramientas para intentar impugnar medidas impopulares tomadas por gobiernos democráticos (...), o tratar de revocar a las autoridades electas" 100 .

Pero, por otro lado, pueden también fomentar un aumento del poder y de la discrecionalidad del Ejecutivo, en detrimento de otros mecanismos de intermediación y representación y, en ese sentido, "promover una democracia de tipo delegativo" 101 .

Conocer por ello, y valorar el modo en que estos mecanismos han sido diseñados y aplicados concretamente en diversos ámbitos, así como sus desempeños y evolución en diferentes contextos económicos y políticos, se vuelve por tanto un desafío oportuno y relevante a corto plazo, para comprender sus potencialidades, pero también sus límites, como estrategias de contestación a la crisis representativa.

\footnotetext{
98 Alicia Lissidini, "Democracia Directa en Latinoamérica: entre la Delegación y la Participación", en S. Pachano (comp.), Temas actuales y tendencias en la ciencia politica, Quito: FLACSO Ecuador, 2008, pág. 130 .

99 Ídem, pág. 130.

100 Ídem, pág. 128.

101 Ídem, pág. 130.
} 


\section{Referencias bibliográficas:}

Abal Medina, J. M. (2004): La muerte y la resurrección de la representación politica; Buenos Aires: Fondo de Cultura Económica.

Abal Medina, J. M. (2010): Manual de ciencia política, Buenos Aires: Eudeba. Brugué, Q; Font, J; Gomà, R. (2003): “Participación y democracia. Asociaciones y poder local, en Funes, M. y Adell; R. Movimientos sociales: cambios social y participación, UNED, Madrid.

Cavarozzi, M. y Casullo, E. (2002): “Los partidos políticos en América Latina hoy: ¿Consolidación o crisis?”, en Cavarozzi, M. y Abal Medina, J. M. (comps.) El asedio a la política. Los partidos latinoamericanos en la era neoliberal; Rosario: Homo Sapiens, pp. 9-30.

Constant, B. (1989): "De la libertad de los antiguos comparada con la de los modernos", Conferencia pronunciada en el Ateneo de París, Febrero de 1819; Centro de Estudios Constitucionales - Universidad de Valladolid.

Fucito, F. (1990): Sociología del Derecho. El orden jurídico y sus condicionantes sociales, Buenos Aires: Editorial Universidad.

García Delgado, D. (1998): “Crisis de representación, nueva ciudadanía y fragmentación en la democracia argentina”, en Gaveglio, S. y Manero, E. (comps); Desarrollos de la teoría política contemporánea; Rosario: Homo Sapiens; pp. 117-144.

García Lema, A. M. (1994): La reforma por dentro. La difícil construcción del consenso constitucional, Buenos Aires: Planeta.

Garretón, M. A. (2001a): Cambios sociales, actores y acción colectiva, CEPAL. Justo López, M. (1963): La crisis de los partidos políticos. Estructura y vigencia en la Argentina, Buenos Aires: Cooperadora de Derecho y Ciencias Sociales, pp. 72.

Ippólito, G. (2007): "Bajo la sombra de Atenas. Avances y Retrocesos de la Democracia Directa en América Latina", Conferencia Internacional Democracia Directa en América Latina, Research Centre on Direct Democracy - UNSAM - IDEA, 14-15 de marzo, Buenos Aires, pp. 1-10, disponible en http:/www.dd-la.ch/download/Ippolito.pdf.

Lissidini, A. (2008): “Democracia Directa en Latinoamérica: entre la Delegación y la Participación", en Pachano, S. (comp.) Temas actuales y tendencias en la ciencia politica, Quito: FLACSO Ecuador.

Manín, B. (1997): The Principles of Representative Government; Cambridge: Cambridge University Press; ISBN 0521-45258.

Nino, C. (1997): La constitución de la Democracia Deliberativa, Barcelona: Gedisa. 
Piedra Buena, C. A. (2007): "Crisis de partidos políticos en la Argentina: aproximación a un diagnóstico de su situación actual", en Ancarola, G. et al Calidad institucional o decadencia republicana, Buenos Aires: Lajouane, pp. 179-204.

Roberts, K. (2002): "El sistema de partidos y la transformación de la representación política en la era neoliberal latinoamericana", en Cavarozzi, M. y Abal Medina, J. M. (comps.) El asedio a la política. Los partidos latinoamericanos en la era neoliberal; Rosario: Homo Sapiens; pp. 55-76.

Rousseau; J. J. (1998): "Del Contrato social”, en Rousseau, J. J. Del Contrato social; Madrid: Alianza Editorial.

Sabsay, D. A. (2007): "La participación ciudadana en la toma de decisiones en el Derecho Público Argentino"; Conferencia Internacional Democracia Directa en América Latina; Organizada por Research Centre on Direct Democracy - UNSAM - IDEA; Buenos Aires; 14 y 15 de marzo, pp. 18; disponible en http://www.dd-la.ch/download/Sabsay_Daniel.pdf.

Sartori, G. (1998): Homo videns. La sociedad teledirigida; Madrid: Taurus; ISBN 84-306-0273-9.

Serrafero, M. (2007): "Calidad institucional: cuestiones y desafíos", en Ancarola, G. et al Calidad institucional o decadencia republicana, Buenos Aires: Lajouane, pp. 13-45.

Taboada, J. (2005): "Democracia Semidirecta en América Latina"; en Observatorio Electoral Latinoamericano; pp. 7; disponible en http:// www.observatorioelectoral.org/informes/documentos/data/2006-04-05juli-taboada.pdf.

Tocqueville, A. (de) (1980): La Democracia en América; Madrid: Alianza Editorial.

Zovatto, D. (2008): "Las instituciones de la democracia directa a nivel nacional en América Latina. Balance comparado: 1978-2007", en Lissidini, A; Welp, Y. y Zovatto, D. (2008): Democracia Directa en Latinoamérica, Buenos Aires: Prometeo. 